\title{
Teach students Semiconductor Lasers according to their natural ability
}

Ken Liu, Chu Cai Guo, Jian Fa Zhang

Ken Liu, Chu Cai Guo, Jian Fa Zhang, "Teach students Semiconductor Lasers according to their natural ability," Proc. SPIE 10452, 14th Conference on Education and Training in Optics and Photonics: ETOP 2017, 104522L (16 August 2017); doi: 10.1117/12.2269780

SPIE Event: 14th Conference on Education and Training in Optics and Photonics, ETOP 2017, 2017, Hangzhou, China 
Teach Students "Semiconductor Lasers" According to Their Natural Ability

\author{
Ken Liu*, Chu Cai Guo, Jian Fa Zhang \\ ${ }^{I}$ College of Optoelectronic Science and Engineering, National University of Defense Technology, Changsha, \\ Hunan 410073, China \\ *Email: liukener@163.com
}

Abstract: Physics explain the world in strict rules. And with these rules, modern machines and electronic devices with exact operation manner have been developed. However, human beings exceed these machines with self-awareness. To treat these self-awareness students as machines to learn strict rules, or to teach these students according to their aptitude? We choose the latter, because the first kind of teaching would let students lose their individual thoughts and natural ability. In this paper we describe the individualized teaching of "semiconductor lasers".

"Semiconductor Laser Physics" is a professional technical course for graduate students in optical engineering [1]. It mainly learns the basic knowledge, dynamics of semiconductor lasers physics, quantum mechanics, laser physics, electromagnetic field theory, and many other disciplines. Through the study of the course, the graduate students should master the physical mechanism of laser based on semiconductor materials, cultivated the ability of graduate students to analyze and utilize different types of semiconductor lasers and develop new semiconductor lasers, and provide strong theory for future research support, and cultivate graduate students self-learning ability, scientific research ability and innovative thinking.

1. Teach students according to their natural ability

Two thousand years ago, the great educator Confucius attaches great importance to the education model of individual education [2]. Once, Confucius finished the lesson, returned to his study, the students Gongxihua gave him a glass of water. At this time, Zilu hurriedly came in, loudly asked the teacher to ask: "Sir, if I heard a correct proposition, can I immediately do it?" Confucius looked sub-road one, slowly said: "Please ask your father and brother, how can we immediately do it?" Zilu just go out, another student Ran has quietly walked in front of Confucius, respectfully asked:" Sir, if I hear the right idea should I immediately do it? "Confucius Immediately answer: "Yes, it should be done immediately." Ran has left, Gongxihua asked strangely:"Sir, face the same question, how you gave the opposite answers?" Confucius smiled and said: "Ran has humble personality, work hesitated, so I encouraged him to be decisive, but the Zilu was brave and acted well, so I was advised to persuade him to listen to others and think twice."

When teaching, we should learn from Confucius. In undergraduate teaching, there are generally a lot of students in one classroom, at this case it is not easy to achieve individualized teaching, or targeted teaching. Different from undergraduate teaching, in general, there were less than 10 students participate in "semiconductor laser physics". In fact, this supplies the possibility

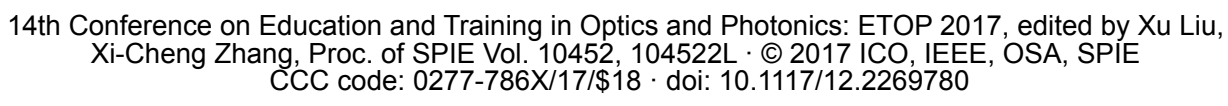


of teaching students according to their individuality. Before the start of the course, we will firstly communicate with these students to understand their background knowledge. Through communication with them, we can understand the personality of these students, which is also necessary for targeted teaching. Because each student's personality is different, background knowledge is not the same, they solve the problem in different way. At the beginning of the teaching, we must also understand these situations.

After the start of the course, we first talk about some solid state physics, semiconductor physics, laser principle and other knowledge. And after students to understand these background knowledge, we then began to explain the semiconductor laser physics related knowledge. For semiconductor laser physics, we do not start deep into quantum physics, but first by explaining the phenomenological theory associated with semiconductor lasers, so that students have a preliminary understanding of semiconductor lasers. The semiconductor laser phenomenological theory does not go deep into the quantum physics of semiconductor lasers, but only from the appearance, the equations of photon and carrier is established mathematically. But this model has been able to solve the semiconductor most of the problems in the application of lasers. In this way, you can let the students from shallow to deep, quickly understand the physical picture of the semiconductor laser. After the students gradually know deeper content, then we will further study the semiconductor laser physics semi-classical theory.

2. Make full use of classroom communication opportunities to mobilize students' subjective initiative.

Classroom teaching should not only focus on teaching, but also actively mobilize the enthusiasm of students to learn from their own. We have tried the introductory teaching in the course. Interest is the best teacher of the student. How to change the course of semiconductor laser physics into a course that students are interested in? Let the students discuss, communicate, exchange and think deeply in the classroom. We have tried the following: students have chosen a course such as semiconductor laser for certain purpose with their own future issues are closely related, we will allow students to research semiconductor lasers in their own applications related with their work. In the classroom, in order to stimulate students to explore new laws and discover new phenomena, so that they master the scientific exploration, we have tried the discussion in the course of teaching, Guiding students' thinking and discussion through carefully prepared cases, and inspired them to take the initiative to think so that they not only grasp the theory, the law, and understand the theory deeply. This can supply more ideas and methods for their future research work.

3. Let students take the initiative to research, read the literature, combined with their own reality, use the knowledge to solve practical problems

The education of the university course should be "giving the skill of fishing" instead of "giving the fish". Let students understand the history of the development of semiconductor lasers, from which they can discover and understand the methods and laws of scientific research. It can also let them avoid taking the wrong way, so that they can stand on the shoulders of the giant. Such as allowing students to investigate the frontier photonic crystal lasers, surface plasmon lasers, 
continuous bound state lasers, and two-dimensional material lasers. This has inspired students' interest, making them feel that traveling in the ocean of knowledge is a very pleasant thing. Students will also be in the classroom about the discussion. In the class they will communicate with each other. Students often discuss their own problems encountered in the subject with the semiconductor laser. They communicate with teacher and other students to. In this way, it formed a good exchange atmosphere. This communication is not limited to the classroom, when the course is over, some students encounter some problems, they will take the initiative to communicate with us, which also allows the "semiconductor laser physics" truly become a lesson that student like to learn. And this also provides a strong theoretical support for their own research. The teachers and students can learn, and communicate and feedback between mutual trust, to avoid the blindness of teaching.

From the actual results, students have approved and supported "semiconductor laser physics" course. The efficient curriculum teaching mode improves the teaching efficiency, makes students study more deeply into their own subjects. More important, the teaching develops and improves the students' ability to independently acquire knowledge, ask questions, analyze problems, and solve problems.

\section{References:}

[1] Coldren, L. A. \& Corzine, S. W. [Diode Lasers and Photonic Integrated Circuits], J. Wiley and Sons: New York, (1995).

[2] Ku Hung-ming, [The Discourses And Sayings Of Confucius], Kessinger Publishing, LLC, (2008). 